\title{
In vitro Wear of Microfilled and Visible Light-cured Composites
}

\author{
P. L. FAN, J. M. POWERS, and R. G. CRAIG \\ School of Dentistry, The University of Michigan, Ann Arbor, Michigan 48109
}

Wear of microfilled composites, a visible lightcured composite, and a conventional composite were characterized by two-body abrasion and single-pass sliding. There were differences in abrasion rates among the materials. Tangential forces, wear track widths, and surface failure modes were different among materials. Wear characteristics are combinations of these properties.

J Dent Res 58(11):2116-2119, November 1979

Introduction.

In vitro wear of restorative materials can be characterized by abrasion testing and singlepass sliding. Two-body abrasion tests have shown different wear characteristics for unfilled resins, composites, and amalgam..$^{1-4}$ Different surface failure modes have been reported for various restorative materials and sealants. ${ }^{3-5}$ Recently, microfilled composites with submicrometer filler particles and composite resins cured by visible light have been introduced. Preliminary clinical applications of these materials have been studied 6,7 However, the in vitro wear characteristics of these materials have not been investigated.

The purpose of this study was to characterize the wear of microfilled and visible light-cured composites by two-body abrasion and single-pass sliding, and to compare the wear characteristics with those of a conventional composite.

Received for publication December 11, 1978 .

Accepted for publication April 30, 1979.

This investigation was presented at the annual meeting of the International Association for Dental Research in New Orleans, LA, March, 1979.

This investigation was supported by USPHS grant No. DE-03416 from the National Institute of Dental Research, National Institutes of Health, Bethesda, MD 20014.

The cooperation of the $3 \mathrm{M}$ Company and Williams Gold Refining Company, Inc. for supplying products used in this study is acknowledged.

\section{Materials and methods.}

Four commercial microfilled composites (IC, IP, MA, and SF), one visible lightcured composite $(F)$ and one conventional, amine-cured composite (C) were studied for their wear characteristics. Product names, codes, batch numbers, and manufacturers are given in Table 1 .

The materials, except $F$, were mixed according to manufacturers' instructions and packed into appropriate molds for curing. Six cylindrical samples $(6 \mathrm{~mm}$ diameter, $12 \mathrm{~mm}$ length) of each material were formed in stainless steel molds. Samples for singlepass sliding were formed in troughs $(5 \mathrm{~mm} \mathrm{x}$ $15 \mathrm{~mm}, 2 \mathrm{~mm}$ deep) cut in acrylic discs (25 $\mathrm{mm}$ diameter, $15 \mathrm{~mm}$ high). All surfaces were cured against glass. Material $F$ was cured using visible light from a tungsten bulb* after passing through a blue filter. The curing time was from two to 20 minutes depending on the size of the sample. All samples were stored in $37^{\circ} \mathrm{C}$ water for 24 hours before testing.

Two-body abrasion experiments were performed using a surface grinder as described by Tillitson, Craig, and Peyton. ${ }^{8}$ Each specimen was abraded under a normal stress of $0.18 \mathrm{MN} / \mathrm{m}^{2}$ against 600 grit $\mathrm{SiC}$ paper ${ }^{+}$moving at $2.5 \mathrm{~mm} / \mathrm{sec}$. The total travel distance was $10 \mathrm{~m}$ on a fresh abrasive surface. Wear debris was removed by a constant jet of distilled water. The length of the specimen before and after abrasion was measured by means of a micrometer accurate to $0.001 \mathrm{~mm}$. The abrasion data are reported as volume of material lost per unit length of travel $\left(\mathrm{mm}^{3} / \mathrm{mm}\right)$.

Single-pass sliding experiments were performed on an apparatus described in detail

\footnotetext{
*Riluma, PN 161, Switzerland

${ }^{+}$Carborundum SiC C600 A965 F, Carborundum Company, Niagara Falls, NY 14032

$\dagger$ Laboratory Supplies Company, Inc., Hicksville, NY 11801
} 
TABLE 1

CODE, PRODUCT NAME, BATCH NUMBERS AND

MANUFACTURERS OF MATERIALS EVALUATED

\begin{tabular}{|c|c|c|c|}
\hline Code & Product & Batch No. & Manufacturer \\
\hline \multicolumn{4}{|c|}{ Conventional composite: } \\
\hline $\mathrm{C}$ & Concise & $\begin{array}{l}\text { Universal } 8 \mathrm{U} 6 \\
\text { Catalyst 8U6 }\end{array}$ & $\begin{array}{l}\text { 3M Company } \\
\text { St. Paul, MN 55101 }\end{array}$ \\
\hline \multicolumn{4}{|c|}{ Visible light-cured composite: } \\
\hline $\mathrm{F}$ & Fotofil & F3762 ADM 44092/76 & $\begin{array}{l}\text { Imperial Chemical } \\
\text { Industries, Ltd. } \\
\text { Macclesfield, Cheshire } \\
\text { England }\end{array}$ \\
\hline \multicolumn{4}{|c|}{ Microfilled composites: } \\
\hline IC & Isocap & 11.79 & $\begin{array}{l}\text { Vivadent } \\
\text { Schaan, Liechtenstein }\end{array}$ \\
\hline IP & Isopast & $\begin{array}{lrl}\text { Base } & 141 & 277 \\
\text { Catalyst } & 281 & 177\end{array}$ & Vivadent \\
\hline MA & Silar & $\begin{array}{l}\text { Paste A MPP501-B7 } \\
\text { Paste B MPP397-B7 }\end{array}$ & 3M Company \\
\hline SF & Superfil & $\begin{array}{l}\text { Universal } 80338 \\
\text { Catalyst } 80329\end{array}$ & $\begin{array}{l}\text { Harry J. Bosworth Company } \\
\text { Skokie, IL } 60076\end{array}$ \\
\hline
\end{tabular}

by Powers and Craig. ${ }^{9,10}$ Six samples of each material were used in this study. Surfaces of the restorative materials were subjected to the sliding of a diamond hemisphere ( $360 \mu \mathrm{m}$ diameter) at a sliding speed of $0.25 \mathrm{~mm} / \mathrm{sec}$. The normal loads were from 1 to $10 \mathrm{~N}$ in increments of $1 \mathrm{~N}$. Tangential force was recorded using a strain gauge transducer. The wear track widths were measured using a calibrated eyepiece in a metallurgical microscope. Surface failure modes were examined using optical microscopy and scanning electron microscopy. The failure modes were classified as: ductile, class 1 ; tensile cracking, class 3 ; and extensive chevron formation, class 5 . Intermediate classifications, classes 2 and 4 , represent a mixture of the above mentioned failure modes. These failure modes have been described by Powers and Craig. ${ }^{11}$

The percent by weight of inorganic filler content was measured gravimefrically. ${ }^{\neq}$ Five samples $(3.7 \mathrm{~mm}$ in diameter and $7.7 \mathrm{~mm}$ long) of each composite were weighed before and after burnout at $500 \mathrm{C}$.

\section{Results.}

The two-body abrasion rates and the percent by weight of inorganic filler content of the restorative materials are shown

\footnotetext{
${ }^{\ddagger}$ Mettler balance H14, Mettler Instruments, Princeton, NJ
}

in Table 2. A one-way analysis of variance ${ }^{12}$ showed significant differences among means of abrasion rate. At the 95 percent level ${ }^{\circ}$ of confidence, the Scheffe interval ${ }^{13}$ was $2.2 \times 10^{-4} \mathrm{~mm}^{3} / \mathrm{mm}$. There were no significant differences among materials IP, IC, $F$, and MA. Materials $C$ and $S F$ were significantly different from the others and from each other. The inorganic filler content of each composite was significantly different from that of the others. At the 95 percent level of confidence, the Scheffe interval ${ }^{13}$ was 0.7 percent.

Average values of tangential forces at various normal loads during single-pass sliding are shown in Fig. 1. The average wear track widths versus normal loads are shown in Fig. 2.

Scanning electron micrographs of wear tracks resulting from single-pass sliding at a normal load of $6 \mathrm{~N}$ are shown in Fig. 3. IC, IP, F and $C$ exhibited class 4 failure; $\mathrm{SF}$, class 3 ; and MA, class 1 . The transition points from one surface failure mode to another occurred at different normal loads for the materials. IC and IP had changes in the modes of surface failure from class 1 to class 4 at $3 \mathrm{~N}$; $\mathrm{C}$ from class 1 to class 4 at $4 \mathrm{~N} ; \mathrm{F}$ from class 1 to class 4 at $6 \mathrm{~N} ; \mathrm{SF}$ from class 1 to class 3 at $6 \mathrm{~N}$; and $\mathrm{MA}$ from class 1 to class 4 at $8 \mathrm{~N}$. Furthermore, the degree of mixing of failure modes in class 4 varied among materials. 
TABLE 2

ABRASION RATES AND INORGANIC FILLER CONTENT OF COMPOSITES

\begin{tabular}{lcc}
\hline \hline Material & $\begin{array}{c}\text { Abrasion rate, } \\
10^{-4} \mathrm{~mm}^{3} / \mathrm{mm} \\
\text { of travel }\end{array}$ & $\begin{array}{c}\text { Inorganic filler content, } \\
\% \text { by weight }\end{array}$ \\
\hline SF & $14.9(0.9)^{*}$ & $35.1(0.4)^{\dagger}$ \\
MA & $12.4(1.0)$ & $49.7(0.7)$ \\
F & $12.2(1.7)$ & $77.7(0.2)$ \\
IC & $12.0(1.2)$ & $33.2(0.1)$ \\
IP & $12.0(0.5)$ & $37.3(0.3)$ \\
C & $6.3(0.4)$ & $76.7(0.1)$ \\
\hline
\end{tabular}

* Mean of six replications with standard deviations in parentheses. The Scheffe interval was $2.2 \times 10^{-4}$ $\mathrm{mm}^{3} / \mathrm{mm}$ of travel.

$\dagger$ Mean of five replications with standard deviations in parentheses. The Scheffe interval was $0.7 \%$.

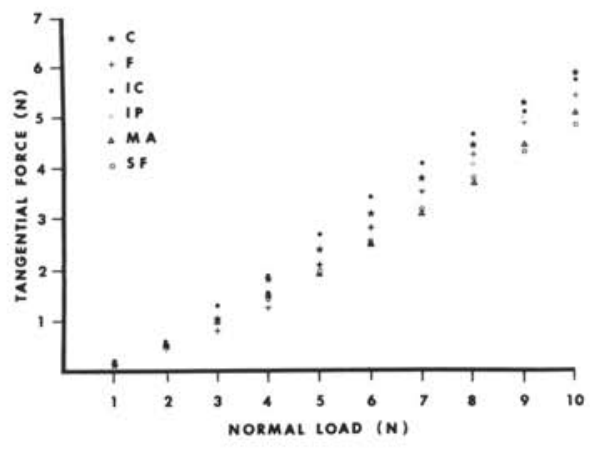

Fig. 1 - Tangential force versus normal load.

to class 4 to $8 \mathrm{~N}$. Furthermore, the degree of mixing of failure modes in class 4 varied among materials.

\section{Discussion.}

The four microfilled composites (IC, IP, MA, and SF) have higher volume loss per unit travel in two-body abrasion than the conventional composite (C). This may result from the smaller amount of inorganic filler incorporated into these materials. Previous studies by Powers, Roberts, and Craig ${ }^{2-4}$ showed that unfilled resins and sealants have higher abrasion rates than filled resins. The microfilled composites have abrasion rates less than unfilled resins, but higher than conventional composites. However, the silica particles used in the micro- filled composites have different sizes and size distributions than conventional composites. A strict comparison based on the amounts of fillers probably is not applicable. Material $\mathrm{F}$ also has a higher abrasion rate than $C$, even though the percentages of inorganic filler are similar. The differences in composition both in the resins and fillers could have considerable influence on the results of two-body abrasion experiments.

There was a similar sequence in wear track widths and abrasion rates. Material

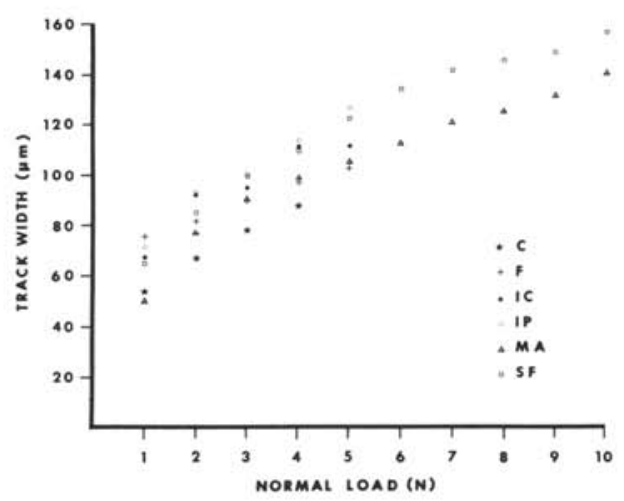

Fig. 2 - Wear track width versus normal load.

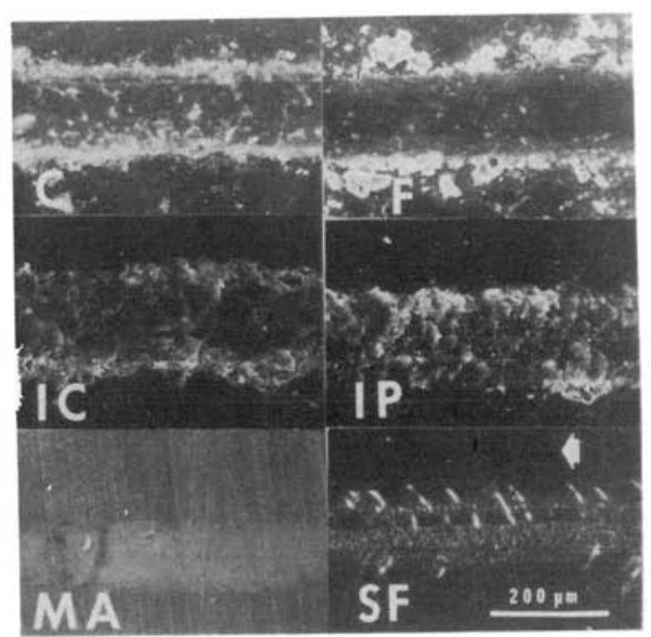

Fig. 3 - Scanning electron micrographs of wear tracks at a normal load of $6 \mathrm{~N}$. Arrow indicates direction of sliding. 
$C$ has the lowest abrasion rate and the narrowest wear track width up to normal loads of $4 \mathrm{~N}$. As the materials reached the class 4 surface failure mode, measurements of wear track width became increasingly difficult. Dislodging of materials by plowing of the diamond slider obscured the boundaries of the wear tracks. Also, the different extents of mixing of failure modes were conspicuous under microscopy. For better information on the wear characteristics of the materials, both the wear track widths and the surface failure morphology have to be taken into consideration.

Tangential forces on single-pass sliding did not have a simple correlation to wear track widths or to abrasion rates. However, at low normal loads $(1-2 \mathrm{~N})$ all materials have similar tangential loads and class 1 failure. At the onset of class 4 failure at higher normal loads, the tangential forces increased appreciably, while at similar normal loads, materials with class 1 or class 3 failure modes had lower tangential forces.

Modes of surface failure involving plowing out of materials (class 4) resulted in considerably higher resistance to sliding and, consequently, higher tangential forces. Materials SF and MA, therefore, had lower tangential forces at higher normal loads $(7-10 \mathrm{~N})$ than the other materials.

Wear of the composites used in this study can be characterized by the following properties: abrasion rate in two-body abrasion; and tangential force, wear track width and surface failure mode in singlepass sliding. All of these properties contribute to the wear characteristics of these materials. The results of this study showed that there are considerable differences in the in vitro wear characteristics of the composites. There are also differences among the microfilled composites.

\section{Summary.}

Two-body abrasion and single-pass sliding tests were used to characterize the wear of four microfilled composites, one visible light-cured composite, and one conventional composite. The abrasion rate of the conventional composite was the lowest. There were differences in abrasion rates, tangential forces, wear track widths, and surface failure modes among the microfilled composites. Lower tangential forces were associated with ductile failure modes. The visible light-cured composite had wear properties more similar to the microfilled composites than the conventional composite. The wear characteristics of restorative materials are a combination of abrasion and mode of deformation during sliding.

\section{REFERENCES}

1. POWERS, J. M.; ALLEN, L. J.; and CRAIG, R. G.: Two-body Abrasion of Commercial and Experimental Restorative and Coating Resins and an Amalgam, JADA 89:1118$1122,1974$.

2. POWERS, J. M.; ROBERTS, I. C.; and CRAIG, R. G.: Wear of Filled and Unfilled Dental Restorative Resins, Wear 39: 117-122, 1976.

3. ROBERTS, J. C.; POWERS, J. M.; and CRAIG, R. G.: Wear of Dental Amalgam, J Biomed Mater Res 11:513-523, 1977.

4. ROBERTS, J. C.; POWERS, J. M.; and CRAIG, R. G.: Wear of Commercial Pit and Fissure Sealants, $J$ Dent Res 56:692, 1977.

- 5. POWERS, J. M.; ROBERTS, J. C.; and CRAIG, R. G.: Surface Failure of Commercial and Experimental Restorative Resins, $J$ Dent Res 55:432-436, 1976.

6. MANNERBERG, F.: Isosit, a New Material for Restoration of Anterior Teeth, Quint Int 8:23-32, 1977.

7. JØRGENSEN, K. D. and ASMUSSEN, E.: Occlusal Abrasion of a Composite Restorative Resin with Ultra-fine Filler - An Initial Study, Quint Int 9:73-78, 1978.

8. TILlITSON, E. W.; CRAIG, R. G.; and PEYTON, F. A.: Friction and Wear of Restorative Dental Materials, $J$ Dent Res 50: 149-154, 1971.

9. POWERS, J. M. and CRAIG, R. G.: Wear of Fluorapatite Single Crystals: I. A Method for Quantitative Evaluation of Wear, $J$ Dent Res 51:168-176, 1972.

10. POWERS, J. M. and CRAIG, R. G.: Wear of Fluorapatite Single Crystals: II. Frictional Behavior, J Dent Res 51:605-610, 1972.

11. POWERS, J. M. and CRAIG, R. G.: Wear of Fluorapatite Single Crystals: III. Classification of Surface Failure, $J$ Dent Res 51:611$618,1972$.

12. University of Michigan, Statistical Research Laboratory: A Manual of Elementary Statistics using MIDAS, Ann Arbor, Statistical Research Laboratory, 1975, $301 \mathrm{p}$.

13. GUENTHER, W. C.: Analysis of Variance. Englewood Cliffs, NJ: Prentice-Hall, 1964, p. 199. 